\title{
Pequenos Brincantes da Educação Infantil: um encontro entre a dança e as culturas populares brasileiras
}

\author{
Fernanda de Souza Almeida \\ Universidade Federal de Goiás - UFG, Goiânia/GO, Brasil \\ E-mail: fefalmeida@gmail.com \\ Andreza Lucena Minervino de Sá \\ Universidade Federal de Goiás - UFG, Goiânia/GO, Brasil \\ E-mail: andrezalucenadesa@gmail.com
}

\section{Resumo}

O presente texto apresenta uma investigação que almejou elaborar, aplicar e refletir sobre uma proposta de intervenção em dança com as crianças goianienses, trazendo em seu cerne, a complexa trama de saberes das culturas populares brasileiras: o lúdico, o conto, a música, o ritmo, o movimento e a dramatização; tendo como principal inspiração, os parques infantis de Mário de Andrade. Para a construção da proposta elencamos, a partir dos estudos vinculados à área temática da pesquisa, três eixos de ação: Fundamentos brincantes, Elementos da dança e Estratégias de abordagem. Com isso, por meio de uma pesquisa-ação, ofertamos 13 encontros, uma vez por semana, ao longo de 4 meses, para duas turmas de crianças com 4 anos de idade, matriculadas em um Centro de Educação Infantil conveniado à prefeitura de Goiânia (GO). Todo o processo foi registrado em diário de campo e dialogado com a teoria elencada. Assim, entre gatos, cachorros, caranguejos, sapos, jacarés coiós, Cacuriás, Cirandas, Jongos, Bumba meu Boi, Capoeira, Catira, cantigas, cordéis, brincadeiras, jogos, brinquedos, adivinhas, palmas, adoletas, mapas do Brasil, vídeos, dobraduras, pinturas, entramos na roda e exploramos palavras, sons, expressões e gestos de modo mágico, metafórico e lúdico. As crianças dançaram e foi possível desenvolver vivências em dança tendo os saberes populares como eixo condutor. Um percurso que nos possibilitou converter-nos em parceiras privilegiadas de novas e infinitas aventuras poéticas com as crianças.

\section{Abstract}

This text presents an investigation that aimed to elaborate, apply and reflect on a proposal of intervention in dance with children from Goiás, bringing in its core, the complex web of knowledge of Brazilian popular cultures: the playful, the short story, the music, the rhythm, movement and dramatization; having as main inspiration, the playgrounds of Mário de Andrade. For the construction of the proposal, we list, from the studiAes linked to the thematic area of the research, three axes of action: Playful fundamentals, Elements of dance and Approach strategies. With this, through an action research, we offer 12 meetings, once a week, over 4 months, for two classes with 4 years old children, enrolled in a Child Education Center associated with the city of Goiânia (GO). The entire process was recorded in a field diary and dialogued with the listed theory. So, among cats, dogs, crabs, frogs, alligators coyós, Cacuriás, Cirandas, Jongos, Bumba meu Boi, Capoeira, Catira, songs, twine, games, games, toys, riddles, palms, teenagers, maps of Brazil, videos, folding, painting, we enter the circle and explore words, sounds, expressions and gestures in a magical, metaphorical and playful way. The children danced and it was possible to develop experiences in dance with popular knowledge as the guiding principle. A journey that enabled us to become privileged partners in new and infinite poetic adventures with children. Keywords

Dance and Early Childhood. Childhood Education. Educational Practices. Traditional Knowledge. 


\section{Comigo não morreu: participantes, local e regras para a brincadeira começar}

No intuito de contribuir com a construção e ampliação do campo epistêmico da Dança na educação da pequena infância, o Grupo de Pesquisa em Dança: Arte, Educação e Infância (GPDAEI), vinculado à Licenciatura em Dança da Universidade Federal de Goiás (UFG), assumiu o desafio de ser explorador. Graduandos/as, docentes e pesquisadoras/es dispostas/os a buscarem o desconhecido, abertas/ os à tentativa, ao risco, a indagar novas possibilidades, reformular trajetórias e a escutar (com todos os sentidos) as pistas que as crianças oferecem, para encontrar caminhos outros - nossos próprios caminhos -, de abordar a Dança na Educação Infantil.

Para tal, nos reconhecemos como artistas que partem das próprias poéticas para favorecer e impulsionar a experiência estética-artística de outras pessoas (CARDONA, 2012). Com isso, indagamos maneiras outras de dançar com a garotada, fomentando o nosso potencial criativo, transmutador, coletor, conector e combinativo para inventar propostas em dança que ampliassem as curiosidades, opiniões e ideias das meninas e meninos de pouca idade.

Concebemos os projetos de dança, intimamente associados ao contexto (ALMEIDA, 2018) que priorizassem a instalação de condições para a vivência da imaginação, inventividade e criação, para que diversos saberes (nossos, das crianças e das/ os profissionais das instituições) fossem dilatados.

Esse percurso desaguou em proposições dançantes multilinguageiras que dialogaram com as tecnologias da informação e comunicação, contação de histórias, desenho, pintura, cinema, música, educação para as relações étnico-raciais, e a temática deste escrito, Dança e as manifestações das culturas populares brasileiras.

A opção pelo tema decorreu do interesse da primeira autora, docente de dança na Educação Infantil, por 14 anos, e em disciplinas da graduação que versam sobre o estágio e as práticas e metodologias de ensino nessa linguagem artística em contextos educativos, em investigar possibilidades outras de abordar a dança com a criançada. Já para a segunda autora, foi seu contato desde a infância com os saberes próprios das culturas nordestinas como o forró pé de serra, a quadrilha junina e a vaquejada, potencializado por diversas disciplinas que transitam pelos caminhos artísticos e metodológicos das manifestações populares na Licenciatura em Dança, UFG, que a impulsionou para a presente pesquisa.

Somado a isso, está a iniciativa de nos aprofundarmos nos estudos de documentos nacionais, estaduais e municipais que norteiam a Educação Infantil. No contexto da cidade de Goiânia, especificamente, há os chamados cadernos Saberes sobre a Infância: a construção de uma Política de Educação Infantil (2004) e Infâncias e crianças em cena: por uma Política de Educação para a Rede Municipal de Educação de Goiânia (2014) ${ }^{1}$, sobre os quais nos debruçamos para verificar a menção da Arte/ Dança e dos saberes tradicionais, em seus escritos.

A partir deles, visualizamos a relevância de apresentar sugestões sobre saberes de Dança e culturas populares a serem oferecidos nas instituições que atendem os pequenos. Ademais, as experiências práticas relatadas ao longo deste artigo podem contribuir com a efetivação da linguagem da Dança na educação, assim como favorecer a formação de professoras/es e possibilitar um maior entendimento de como as propostas da rede municipal de ensino de Goiânia podem permear a jornada educativa em relação à Dança. Fatores que podem inspirar e serem ampliados para outros contextos brasileiros.

\footnotetext{
1 Para saber mais sobre a menção da Dança e dos elementos das culturas populares brasileiras, assim como a escassez de aprofundamentos, contextualizações, sistematizações e detalhamentos metodológico e/ou teórico nos textos de ambos os documentos referendados, acessar: SÁ, Andreza Lucena Minervino. Pequenos brincantes da Educação Infantil: uma proposta em dança e culturas populares brasileiras. Monografia (Licenciatura em Dança), Universidade Federal de Goiás, 2018. ALMEIDA, Fernanda de S.; SÁ, Andreza L. M. de. Políticas Educacionais e o Contexto Goianiense: horizontes para a Dança com a Educação Infantil. Anais VI Congresso Internacional dos Arte/Educadores e XXVIII Congresso Nacional da Federação de Arte/Educadores do Brasil, Brasília: Federação de Arte/Educadores do Brasil, v. 1, p. 2432-2447, 2018.
} 
Por fim, ao buscarmos maiores conhecimentos sobre as culturas populares na Educação Infantil, nos deparamos com os Parques Infantis (PI) idealizados por Mário de Andrade (MA)2 implantados em 1935, na cidade de São Paulo. Segundo Faria (1999), os PI tinham o intuito de promover atividades educativas para crianças de 3 a 6 anos de idade, sendo seu foco a valorização das culturas brasileiras direcionada para essa gente pequena, de modo que atendesse suas necessidades e curiosidade específicas. Nesse sentido, identificamos os escritos de Mário de Andrade como uma inspiração para essa investigação, uma vez que ele foi o primeiro idealizador de uma ação em educação que envolvesse criança e culturas populares.

Sob o contexto apresentado e amparadas pelo que versam os documentos federais, estaduais e municipais sobre uma educação cultural, especialmente a parte que toca nos conhecimentos produzidos historicamente e as diversas linguagens da arte, dentre elas a dança, emergiu a problemática desta pesquisa, a saber: como desenvolver uma proposta em dança com meninas e meninos da Educação Infantil tendo como eixo central os saberes das culturas populares brasileiras?

Diante de tal questionamento nos aventuramos em um estudo que objetivou elaborar, aplicar e refletir acerca de uma proposta de intervenção em dança com as crianças goianienses, trazendo em seu cerne a complexa trama de saberes das culturas populares brasileiras: o lúdico, o conto, a música, o ritmo, o movimento e a dramatização, tendo como principal inspiração os PI de Mário de Andrade.

Para responder a problemática aludida buscamos a metodologia de pesquisa qualitativa, compreendendo que os estudos em educação são fluídos e dinâmicos por estarem situados em um contexto social particular e em uma realidade histórica em

2 Mário de Andrade foi um dos artistas participantes de um projeto nacionalista de identidade brasileira, sendo muito criticado por estudiosos das culturas populares. Entretanto, o recorte desta investigação refere-se apenas aos $\mathrm{PI}$, por ser essa uma primeira experiência em Educação Infantil que valorizou as crianças como sujeitos, tendo as culturas populares como um dos eixos educativos. constante transformação (MENGA; ANDRÉ, 1986). Essas características se aproximaram deste trabalho, uma vez que investigamos a presença ou a ausência da Arte/Dança nas propostas pedagógicas para as instituições de Educação Infantil em Goiás. Em seguida, realizamos um paralelo com as proposições dos PI no que tange a cultura e o lúdico, refletimos sobre nossas experiências com as manifestações das culturas populares brasileiras e com a infância, e observamos a comunidade escolar para que, pudéssemos elaborar e realizar uma possibilidade de intervenção dançante com as crianças.

Além do mais, dado o papel propositivo, integrador e atuante desempenhado por nós, pesquisadoras, esse estudo teve caráter de pesquisa-ação. Nesse sentido, Thiollent (1986) alega, para a escolha dessa abordagem, que as/os investigadoras/res trabalhem com ações devidamente planejadas, sejam de caráter social, educacional, técnico ou de qualquer outra natureza.

No campo educacional, muitas vezes, esse tipo de pesquisa é utilizado no sentido de buscar possibilidades outras para o fazer pedagógico para um determinado grupo, refletindo sobre a própria prática educativa de maneira crítica e transformadora em associação com as/os participantes e em diálogo frequente com o embasamento teórico. Contudo, devido as limitações textuais com relação à dança, a pesquisa será apresentada em formato de relato de experiência.

Todo o processo foi descrito em diário de campo, objetivando retratar as vivências, bem como as reflexões das pesquisadoras, as avaliações dos planos de ação e a participação do contexto nas decisões, nas sugestões, nas escolhas dos materiais, das vivências, das brincadeiras e músicas, além de evidenciar os principais apontamentos acerca da mudança do ponto de vista das crianças, das professoras $^{3}$ e nosso, no decorrer das intervenções.

3 Essa investigação foi aprovada pelo Comitê de Ética e Pesquisa (CEP/UFG) sob o n. 51819415.60000 .5083 e contou com os termos de assentimento, anuência e consentimento livre e esclarecido das/os envolvidas/os e responsáveis, bem como a autorização para uso de imagens para fins investigativos e educativos. Os termos, além da descrição detalhada dos planos de ação dos encontros e diários de campo, encontram-se nos arquivos do GPDAEI. 
Assim, a presente pesquisa é o resultado do trabalho realizado com duas turmas de crianças com 4 anos de idade, matriculadas em um Centro de Educação Infantil (CEI) conveniado da prefeitura de Goiânia, distribuídos em 13 encontros, ofertados uma vez por semana, tendo entre 30 e $45 \mathrm{mi}-$ nutos de duração cada, durante um semestre letivo.

\section{Quem vai brincar, põe o dedo aqui:} selecionando os eixos de ação da proposta

Para a construção da proposta dançante elencamos três eixos de ação, sem fragmentações ou ordenamentos, os quais dialogam intensamente entre si:

1) Fundamentos brincantes: inspirados nos PI de Mário de Andrade. Consiste em múltiplas linguagens, pesquisa e vivências dos saberes das culturas tradicionais; jogos tradicionais infantis, rodas cantadas, cantigas, contos, rimas, adivinhas, parlendas, danças de roda e dramatizações;

2) Elementos da dança: utilização de recortes das sistematizações realizadas por Almeida $(2016,2018)$ e Andrade (2016), principalmente, as ações corporais, partes do corpo, níveis, direções, apoios, ritmo, peso e tempo;

3) Estratégias de abordagem: propostas advindas de Almeida $(2016,2018)$ e Andrade (2016), tais como o lúdico, a educação e apreciação estética e a interação, somados aos princípios pontuados por Oliveira (2011), a saber: repetição / improvisação; interdisciplinaridade / presença; ritmo / musicalidade e a relação / percepção do outro, do espaço e de si mesmo no espaço.

Os Fundamentos brincantes abrangem o conceito de cultura e cultura popular ancoradas nas discussões de Oliveira (2011), que discorre acerca de tais termos sob o viés de que todos possuem cultura e nenhuma é superior a outra. Essa compreensão nos incentiva a abordar os elementos das manifestações criativas e orgânicas da população brasileira de maneira crítica, contextualizada, dinâmica e respeitosa, contemplando a profundidade e a complexidade do tema.
Elia (2017) relata que Mário de Andrade entendia a identidade brasileira de forma lúdica e inventiva, por isso idealizou os Parques Infantis, um projeto de educação da infância posto em prática quando ele foi diretor do Departamento de Cultura da prefeitura de São Paulo, entre 1935 a 1938. Segundo Paula (2012), Mário foi um escritor, poeta, etnógrafo e crítico de música, literatura e artes plásticas. Também foi um admirador das culturas brasileiras, sendo um dos seus projetos a promoção e a nacionalização da arte e da cultura do Brasil.

Além do mais, Mário considerava a criança como produtora de cultura, assim o cotidiano dos Parques Infantis possuía uma estrutura menos rígida, na qual a criançada, em conjunto com os responsáveis, organizava as próprias atividades, como jogos (sociais e sensoriais), brincadeiras diversas, ginástica, natação, arte, artesanato e os saberes das manifestações tradicionais das culturas brasileiras, como teatro, dança, desenho, jardinagem, modelagem e outros (ELIA, 2017).

Tal prática educativa dos Parques Infantis, de acordo com Faria (1999) e Paula (2012), oferecia uma diversidade singular de experiências éticas, estéticas, lúdicas, artísticas, corporais, por meio da educação da cultura, alinhada ao cuidado infantil. Paula (2012) afirma que essa proposta de Mário de Andrade foi e é inovadora por estruturar-se no binômio educação-cultura e valorizar as diferentes linguagens expressivas, como a verbal, musical, corporal, poética, visual e outras. Ademais, o trabalho com as danças populares não acontecia de forma escolarizada, mas de maneira ampla, na qual a intenção era voltada para a vivência e a experiência sensorial.

Conforme Pizani, Júnior e Amaral (2016), as crianças que vivenciavam os Parques Infantis tinham atividades de levantamento e registro das cantigas, brincadeiras e danças que aprendiam com seus familiares. Delegar uma pesquisa dessa natureza à garotada era reconhecê-la como sujeitos de direitos, autônomos, capazes de tomar decisões e criar a partir do contato com a cultura. 
No que concerne, precisamente, à dança nos $\mathrm{PI}$ :

[...][as atividades] eram ofertadas às crianças entre três a seis vivências na semana, sendo inicialmente abordadas as rodas cantadas com imitações e figurações simples, assim como, as letras das músicas. Para as crianças maiores eram introduzidas danças, as quais deveriam ser organizadas com passos precisos e ritmados, apresentando um caráter utilitário, relacionado aos benefícios dos exercícios. As orientações sugeriam ainda que as danças fossem preferencialmente ligadas a temas da cultura popular, retratando a forte influência da construção de uma identidade nacional que se materializava nos corpos e nas cidades, nas carnes e nas pedras. (PIZANI; JÚNIOR; AMARAL, 2016, p. 11).

As estratégias que envolvem imitação e reprodução gestual das letras das músicas e treinamento dos passos, para uma abordagem da dança com a infância, na atualidade, é alvo de amplas discussões. As pesquisas acadêmicas apontam para caminhos que valorizem vivências autorais, entretanto, ainda é comum, nos espaços educativos, ações baseadas apenas na cópia desprovida de significados, com objetivos diretamente ligados ao caráter utilitário e virtuoso (ALMEIDA, 2017).

Entendemos a imitação como uma possibilidade de se trabalhar a dança com a meninada, principalmente, quando ela é vinculada ao faz de conta e desde que não impeça a reelaboração das experiências infantis (ALMEIDA, 2017). Além do mais, dependendo de como a imitação é mediada, é possível explorar a in-corporação dos conceitos em dança, com a apropriação do movimento e a conscientização do corpo. A repetição pode evocar a profundidade.

Ainda sobre a imitação, recorremos a Dornelles e Miceli (2016) por considerarem que:

[...] as crianças não se limitam a imitar apenas o que fazem os adultos, elas interpretam a seu modo a realidade e a cultura e as reproduzem a partir de sua compreensão, e dessa maneira produzem suas culturas, as culturas infantis. (DORNELLES; MICELI, 2016, p. 3).
Ademais, as danças tradicionais possuem seus próprios códigos, desse modo o aprendizado dos passos torna-se parte do processo. A questão é: quais estratégias são utilizadas para ensiná-los? Acreditamos numa abordagem que não seja pautada na mimetização das letras de música ou na reprodução utilitarista dos gestos, uma vez que entendemos que a dança não se resume a passos pré-codificados ou elaboração de coreografias. Ela é uma área de conhecimento que lida com os saberes do corpo e com a criação e experiência artística, estética e poética.

Em relação aos Elementos da dança concebemos a Dança como uma linguagem da Arte que precisa ser pensada a partir das singularidades dos sujeitos, respeitando e valorizando a expressividade e as particularidades de movimentação e apropriação das suas gestualidades.

A esse respeito, para Andrade (2016) é importante que a investigação do corpo seja apresentada à garotada de maneira divertida, para que possam ter uma compreensão acerca de sua estatura e estruturas (ossos, músculos, articulações, pele, partes corporais), apreendendo, assim, o que possuem de igual ou diferente em relação ao próximo.

Nesse contexto, alguns autores se dedicaram a organizar os elementos próprios da dança a serem oferecidos na Educação Infantil. Dentre eles destacamos Almeida (2016; 2018), que sistematizou os elementos da dança em: Corpo, Movimento Expressivo, Espaço e Ritmo; e Andrade (2016), que apresenta os conhecimentos de dança sob três aspectos, denominados temáticas da dança, divididos em: corpo; fundamentos da dança e criação em dança ${ }^{4}$.

Ambas as autoras entendem a dança como um campo com conhecimentos específicos, possíveis de serem vivenciados com diferentes sujeitos, necessitando apenas de abordagens lúdicas apropriadas.

4 Para mais detalhes, consultar: ALMEIDA, Fernanda de S. Que dança é essa? Uma proposta para a educação infantil. São Paulo: Summus, 2016; ALMEIDA, Fernanda de S. Dança e educação: 30 experiências lúdicas com crianças. São Paulo: Summus, 2018; ANDRADE, Carolina R. Dança para criança: uma proposta para o ensino de dança voltada para a educação infantil. Tese (Doutorado em Artes), Universidade Estadual Paulista, São Paulo, 2016. 
Lukesi (2005) aponta que a atividade lúdica é aquela que propicia a plenitude da experiência. Para o autor, vivenciar uma experiência lúdica é estar plenamente presente, é visar apenas a própria experiência de modo que haja uma integração mental, emocional e física. Constitui-se, desse modo, em um mergulho pessoal diferente e singular para cada sujeito que a vivencia.

Além do lúdico, outra estratégia de abordagem que encontrou ressonância nessa pesquisa, foi a educação estética, que para Ostetto (2011) é uma educação do ser poético. Visa a ampliação dos saberes, sabores, repertórios vivenciais e culturais, possibilitando o exercício da sensibilidade, mobilizada por todos os sentidos, na totalidade do olhar, da escuta, do movimento e do sentir. A educação estética proporciona outras percepções que tangem o mundo de forma poética, mitológica, simbólica, metafórica e contemplatória.

Sob tais aspectos, na arte do inusitado, ou o inusitado na arte, provoca e convida a ouvir, degustar, brincar, experienciar, cantar e dançar. Com isso, como as culturas populares e as crianças são essencialmente linguageiras, as múltiplas linguagens podem ser um caminho para as vivências em dança no encontro com a fotografia, música, mídias, movimento, esculturas, desenhos, poesia, dramatização, jogo e muitos outros campos do conhecimento.

A imitação, entendida aqui como reprodução interpretativa (CORSARO, 2011), apesar de "uma atividade polêmica no meio educacional, pode ser, nessa fase da infância, interessante, adequada e não tolher o potencial criativo da criança" (ALMEIDA, 2017, p. 508). Por meio dela a garotada pode compreender o movimento, reelaborá-lo à sua maneira, encontrando possibilidades outras de produzir seus próprios sentidos.

Já sobre a importância de se vivenciar o universo das brincadeiras populares, Oliveira (2011) destaca alguns princípios que ajudam a pensar as culturas populares como uma das referências metodológicas para o trabalho com teatro em âmbito educativo formal, as quais, adaptamos ao contexto da dança.
A autora frisa que o intuito não é transferir os fazeres das culturas populares para a escola, mas usar alguns elementos das festas e brincadeiras como um caminho para a construção de conhecimentos. Dessa maneira, o primeiro princípio apontado é o da repetição/improvisação, muito comuns nas manifestações populares que, apesar de terem códigos e regras estabelecidos, abrem espaço para o riso, a repetição, o lúdico e para a improvisação.

A interdisciplinaridade/presença trata da variedade de habilidades que a/o brincante pode executar dentro da brincadeira como cantar, tocar, dançar, relacionar-se com o espaço e com o outro simultaneamente. Esse aspecto possibilita paralelos entre as diversas linguagens da arte que podem ampliar os repertórios corporais e de movimentos da criançada, bem como propiciar experiências estéticas de expansão dos sentidos e das noções de corpo.

O princípio do ritmo/musicalidade aponta que nas brincadeiras populares há uma forte presença musical que contribui para o desenvolvimento da percepção rítmica, auxiliando os meninos e meninas na apreensão dos diversos tempos, velocidades, pausas e impulsos de movimentos.

Por fim, a relação com o outro e com o espaço é um caminho relevante nas vivências dançantes e nas manifestações expressivas das culturas populares brasileiras com as crianças pequenas, pois a relação com o espaço em dança está presente nos deslocamentos, nas direções e nas trajetórias do movimento pelo espaço. Além do mais, é no contato com os pares que ocorre a produção cultural das/os pequenas/os brincantes, e são desenvolvidas as expressões multilinguageiras.

\section{Dolê 1, dolê 2, dolê 3:}

\section{os pequenos brincantes dançantes em ação}

Com o intuito de experimentar a sistematização dos três eixos apresentados, iniciamos as aproximações ao campo de ação, seguido dos encontros dançantes.

O primeiro contato se deu por uma visita à escola, objetivando conhecer o espaço educativo, gestoras/es, professoras/es, demais funcionárias/ 
os e a criançada, bem como organizar a agenda de datas e horários das duas turmas participantes.

Após os acordos realizados com a gestão institucional, empreendemos dois dias de observação participante da jornada educativa, almejando inserir o projeto de dança integrado às necessidades e particularidades do contexto em que estávamos presentes. Nesse sentido, buscamos perceber quais dimensões do movimento as crianças já acessavam, o que conheciam do corpo e quais eram suas experiências com elementos e/ou manifestações das culturas tradicionais brasileiras.

No segundo dia de observação, motivadas pelo estudo dos Parques Infantis, que apontava a importância de conhecer a cultura das crianças e das famílias para que as propostas fomentassem significados e sentidos para a garotada, decidimos conversar com as crianças sobre suas músicas e brincadeiras favoritas. Também, escolhemos, previamente, algumas cantigas do cancioneiro popular infantil, no ensejo de saber se identificavam alguma delas (ou outras) e se conheciam alguma brincadeira ou dança de roda.

Organizamos e entregamos um questionário às famílias, que procurava descobrir as cantigas populares, brincadeiras ou danças de roda conhecidas e praticadas em suas tenras idades. Tal ação estava em consonância com Dornelles e Miceli (2016, p. 3), por apontarem que "as famílias são os primeiros grupos sociais cujas crianças participam, tornando-se, assim, fortes influências que colaboram diretamente para a formação das culturas infantis". Portanto, conhecer as experiências familiares, contribuiu para uma aproximação mais significativa com a meninada.

As respostas mais recorrentes foram brincar de esconde-esconde, cantigas como Atirei o pau no gato, Alecrim Dourado, Ciranda Cirandinha e os contos do Saci Pererê e da Mula sem cabeça. Com isso, percebendo que a característica das cantigas era recorrente, tanto no contexto familiar, quanto no Centro de Educação Infantil, decidimos começar as vivências partindo dessa convergência de conhecimento.

Nosso objetivo era apresentar à essa gente miúda a diversidade da cultura brasileira, reviven- do algumas tradições populares de variados lugares do Brasil. A estratégia foi partir do que os pais e crianças discriminaram no questionário. Depois fizemos um apanhado das experiências infantis das/os funcionárias/os e professoras/es, seguindo posteriormente para as culturas brasileiras.

De nossa parte, destacamos que não havia um plano de ação pronto desde o início. As vivências eram pensadas encontro a encontro. Optamos por esse caminho pelo fato de ele nos possibilitar uma escuta mais sensível e atenta às necessidades e curiosidades da garotada. A esse respeito, Buss-Simão comenta que "ouvir as indicações das crianças oferece pistas que podem contribuir para a construção da especificidade da docência com crianças pequenas a qual envolve uma grande quantidade de ações" (2014, p. 103).

Ao longo do fazer, perpassamos pelas poesias em formato de cordel para, por exemplo, apresentar as regras de convivência que elaboramos coletivamente.

\section{Figura1 - Apresentação dos combinados em} cordel.

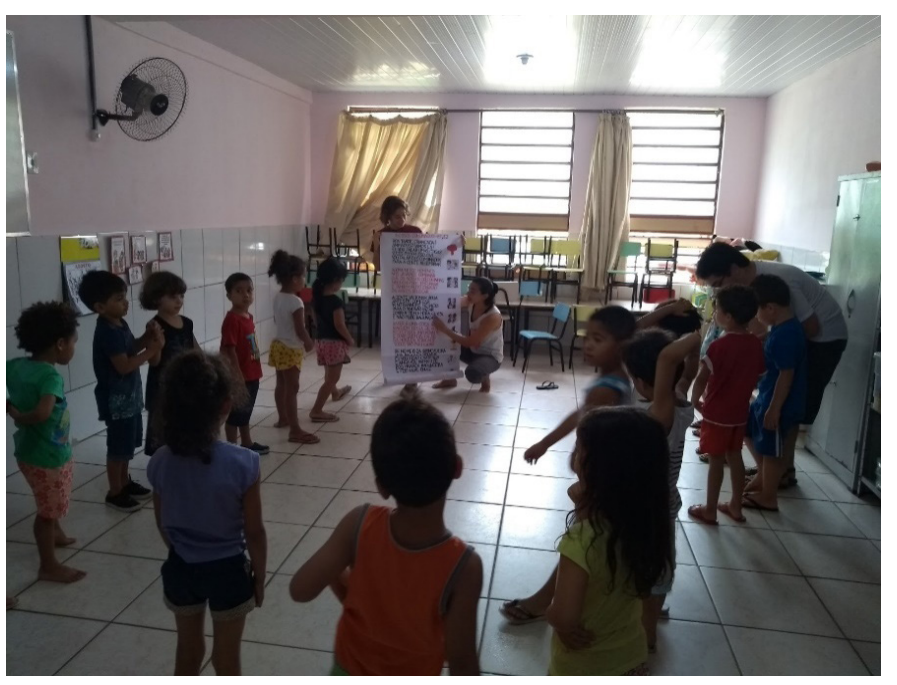

Fonte: Araújo (2018).

Por meio da arte e da poesia, especialmente do cordel, foi possível transformar uma leitura de "regras" que geralmente é uma coisa chata para a pequenada, em uma coisa divertida, prazerosa e interessante. Essa é uma estratégia que pode ser adotada pelas/ os professoras/es, pois não fica muito apegada ao lugar do não pode. Na escrita do 
cordel, podemos usar de uma licença poética que vai brincando com as palavras. $\mathrm{O}$ mesmo pode acontecer apresentando os combinados em forma de história ou música. (DIÁRIO DE CAMPO, 04/09/2018).

Discorrendo sobre a poesia infantil, Ostetto (2011) menciona que se trata de um dos meios de criar linguagens e de se aproximar da lógica particular e característica das crianças. Sobre isso, notamos que a poesia de cordel foi uma abordagem diferente e interessante para essa gente de pouca idade.

Além disso, imitamos e dançamos os personagens das músicas e contos tradicionais, tais como um gato, buscando relacioná-lo aos elementos da dança: apoios, ações corporais, níveis e espaço. Solicitamos, na sequência, que cada criança criasse a própria dança do seu gato, utilizando, combinando e ampliando os elementos/gestos sugeridos por nós.

As múltiplas linguagens também foram o eixo central da maioria das intervenções. Em uma delas, iniciamos com a confecção e pintura de cachorros em origami e, em seguida, contamos uma pequena história criada por nós, que narrava o encontro do cachorro com o caranguejo, fazendo assim, uma ponte entre o encontro dançante anterior e o atual de modo que houvesse um contínuo entre as proposições.

Construímos essa vivência a partir dos elementos do Cacuriá dança típica do estado do Maranhão, que acontece em roda ou "cordão", e compõe as festas da tradição junina, como parte das festividades do Divino Espírito Santo. Utilizamos recursos midiáticos de vídeo e imagens para apresentar o caranguejo à criançada e levamos impressa uma imagem com o mapa dos estados brasileiros, para localizar o Maranhão. Além de cantar, dançar e brincar o "caranguejinho tá andando, tá na boca do buraco, caranguejo sinhá".

Horas depois dessa vivência observamos algumas crianças no parquinho reproduzindo as proposições dançantes do gato e do caranguejo. Essa transferência da brincadeira está em conformidade com o que Corsaro (2011) denomina de cultura de pares, grupos de ações e/ou atividades, rotinas, valores e preocupações que essa gente de pouca idade compartilha nas interações com outras crianças, reelaborando-as à sua maneira. Foi uma satisfação saber que elas estavam incorporando os saberes da dança e levando-os para outros momentos de seus cotidianos.

Assim, entre gatos, cachorros, caranguejos, sapos, jacarés coiós, Cacuriás, Cirandas, Jongos, Capoeiras, Catiras, cantigas, cordéis, brincadeiras, jogos, brinquedos, adivinhas, sapateados, palmas, adoletas, "feijão com arroz", mapas do Brasil, vídeos, dobraduras, pinturas, entramos na roda e exploramos as palavras, os sons, expressões e gestos de modo mágico, metafórico e lúdico, ou seja, um escape do ordinário para o extra-ordinário.

A esse respeito, Ostetto (2011) relata a importância de se construir práticas pedagógicas que alarguem as oportunidades de acesso à riqueza da produção cultural, promovendo a aproximação das crianças com os diferentes códigos estéticos e ampliando seus repertórios vivenciais e culturais. Esse foi o ponto central dessa pesquisa, uma vez que procuramos expandir os conhecimentos e experiências, nossas e das crianças, estabelecendo trocas e encorajando a experimentação, a invenção e a autonomia.

Para finalizar o relato da experiência em campo, compartilhamos a intervenção do Bumba meu boi maranhense por ter sido, uma das manifestações da cultura popular mais pesquisada por Mário de Andrade e esteve presente nas atividades desenvolvidas nos Parques Infantis. Essa foi a vivência em que mais utilizamos as diferentes linguagens, mesclando conto, dança, dramatização, musicalidade, apreciação e educação estética.

A mediação baseou-se sob o que Rosseto (2012, p. 45) nomeia de professor/a-personagem, isto é, "um recurso que subsidia a criação de uma atmosfera cênica, impulsionando a teatralidade no espaço de ensino". Ora assumíamos as características de narradoras do conto do boi, ora nos transfigurávamos em fazendeiras, bois, vaqueiras ou Catirina ${ }^{5}$. Uma faceta docente artística que aproximou as crianças do estado de in-

5 Personagens de uma das narrativas do bumba meu boi. 
terdisciplinaridade/presença (OLIVEIRA, 2011), oportunizando a diversificação das experiências estéticas.

\section{Figura 2 - Vídeo e encenação do conto com a} boneca Catirina e o Boi.

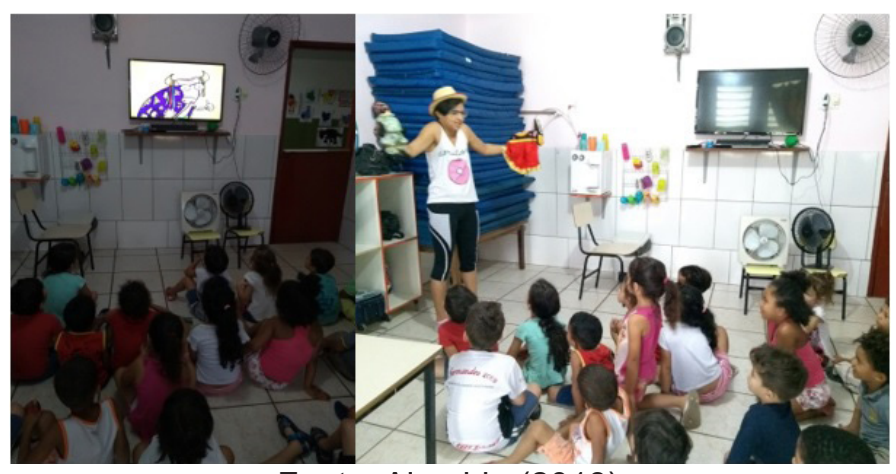

Fonte: Almeida (2018).

Figura 3 - Apreciação do toque da caixa e roda de Boi.
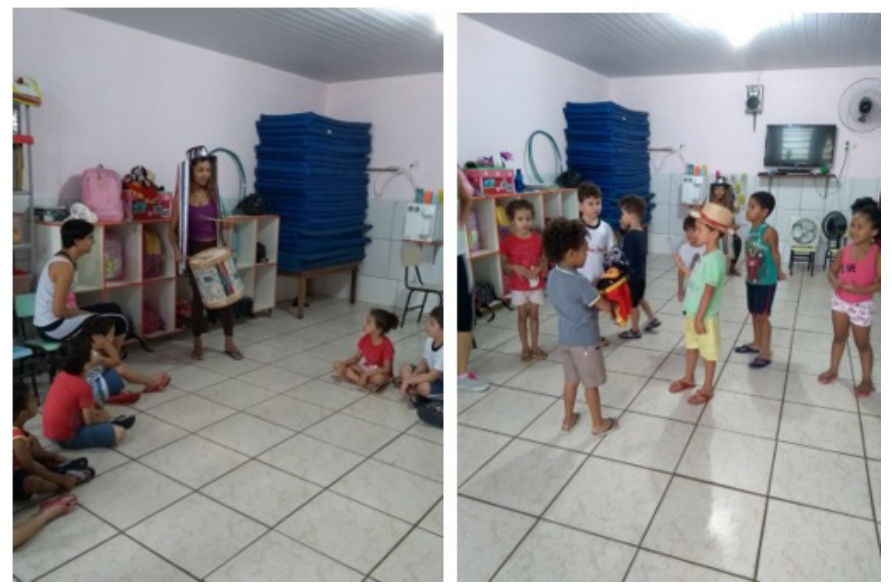

Fonte: Almeida (2018)

O toque e a presença da caixa fizeram toda a diferença nesse encontro, visto que propiciou uma maior percepção do ritmo que conduziu o movimento. Conseguimos cantar e dançar na roda, as duas músicas elencadas no plano de ação, e foi muito surpreendente observar a criançada em suas explorações, perceber como já ampliaram as percepções do corpo e suas partes, como estão mais claras para eles as relações e conexões estabelecidas no gesto e no movimento. (DIÁRIO DE CAMPO, 23/10/2018).

Por meio de risadas, gesticulações e catarses, notamos que esse foi o encontro em que as crianças mais se divertiram. Todas queriam andar ao som da caixa, explorando, em diferentes direções, o encantar do vaqueiro, o ataque do boi, a movimentação da roda, o girar e vários outros elementos rememorados dos encontros anteriores. Ostetto (2011) alerta que:

[...] um dos papeis do professor é abrir canais para o olhar e a escuta sensíveis, disponibilizando repertórios (imagéticos, musicais, literários, cênicos, fílmicos), não apenas para a realização de uma atividade, mas, inclusive, cuidando do visual das salas e dos demais espaços da instituição. (OSTTETO, 2011, p. 6).

Procuramos levar o máximo de materiais que pudessem provocar e auxiliar a meninada nas experimentações, descobertas, criações e imaginações.

Ao final desse e de tantos outros encontros, era nítido que a pergunta desta pesquisa estava sendo respondida, pois as crianças dançaram tendo os saberes populares como eixo.

\section{Um, dois, três, salve o mundo: esboçando os próximos passos}

Ao longo do percurso de pesquisa, além de notarmos como os elementos das culturas populares brasileiras podem ser uma estratégia interessante para abordar a dança com as crianças, nos deparamos com as características da diversidade, da ampliação das perspectivas sobre cultura, dança, das relações sobre si, sobre o corpo e sobre o outro.

Os muitos desafios que a docência com a pequena infância nos apresentou, como desatenção, choro, brigas, manhas, enfrentamentos, resistências e situações adversas e caóticas contribuíram exponencialmente com a nossa formação. Como lidar com o que escapa ao planejado? Como reconhecer outra ordem, outro jeito de conceber, fazer e dialogar, a partir da alteridade da criança?

Ao planejar as atividades, por vezes, nós, professoras/es, imaginamos que ela acontecerá de acordo com nossas expectativas, e a criançada corresponderá exatamente como descrito no plano. Entretanto, é preciso ter a clareza de que a lógica infantil é diferente da adulta, elas exploram e viven- 
ciam as brincadeiras a partir das suas referências e reelaborações, portanto, mesmo que pareça, por vezes que a proposta virou uma grande confusão, elas estão sim experimentando e produzindo significados sobre o que foi proposto. Contudo, a sua maneira, sob as especificidades do contexto infantil. (DIÁRIO DE CAMPO, 27/11/2018).

Ampliamos nosso olhar para além do que estava visível, nos levando a perceber outros detalhes e sutilezas que muitas vezes estavam presentes de modo subliminar. Nesse sentido Buss-Simão relata que:

\begin{abstract}
[...] incluir, nas ações pedagógicas, a perspectiva das crianças exige também recuperar valores e conhecimentos que incluem o corpo e suas expressões, o movimento, o gesto, o afeto, as emoções, a ludicidade, o encantamento e o maravilhamento e, sobretudo, valores e conhecimentos capazes de lidar com as polissemias e com as complementaridades, inclusive a complementaridade proporcionada pela contribuição única que as crianças podem dar, a partir da sua condição geracional, diferente daquela advinda do mundo social de pertença dos adultos. (BUSS-SIMÃO, 2014, p.108).
\end{abstract}

Talvez tenha sido esse nosso maior aprendizado: deslocar o olhar e a perspectiva adulta que produz e organiza o mundo para as crianças e entender que, no contexto educacional, as relações acontecem a partir das crianças e com elas. Convertemo-nos, então, em parceiras privilegiadas de novas e infinitas aventuras poéticas!

Ademais, evocamos, segundo Cardona (2012), uma presença integradora, provocativa, estimulante e apaixonada da nossa docência artística, que usou o corpo, a voz, um ritmo cênico e toda uma expressividade, ora de mistério, ora de desafio ou jogo, para nos relacionarmos com os saberes da dança e com as crianças durante a proposição das vivências.

Por fim, destacamos que o contexto educacional que encontramos antes de nossas intervenções foi modificado pelas professoras regentes, que ressignificaram suas práticas docentes depois da realização do projeto na instituição. As próprias crianças comentavam, durante as atividades, que estavam utilizando as vivências da dança em outros momentos, tais como no parque, em trocas com os pares e na relação com os adultos. Um processo fundamentado na partilha.

\section{Referências}

ALMEIDA, Fernanda de S. Que dança é essa? Uma proposta para a educação infantil. São Paulo: Summus, 2016.

ALMEIDA, Fernanda de S.; SÁ, Andreza L. M. de. Políticas Educacionais e o Contexto Goianiense: horizontes para a Dança com a Educação Infantil. Anais VI Congresso Internacional dos Arte/Educadores e XXVIII Congresso Nacional da Federação de Arte/Educadores do Brasil, Brasília: Federação de Arte/Educadores do Brasil, v. 1, p. 2432-2447, 2018.

Siga O Mestre: Reflexões sobre Dança, Imitação e Educação Infantil. Revista Contemporânea de Educação, v. 12, p. 504-520, 2017. Disponível em: https://revistas.ufrj.br/index.php/rce/article/ view/3650. Acesso: 14 nov. 2020.

Dança e Educação: 30 propostas lúdicas com crianças. São Paulo: Summus, 2018.

ANDRADE, Carolina R. Dança para criança: uma proposta para o ensino de dança voltada para a educação infantil. Tese (Doutorado em Artes), Universidade Paulista, São Paulo, 2016.

BUSS-SIMÃO, Márcia. Relações sociais na educação infantil: olhar sobre o corpo e os sentimentos. Educação, Porto Alegre, v. 37, n. 01, p. 101-109, 2014.

CARDONA, Patricia. La poética de la enseñanza. Uma experiencia. México: Cenidi Danza/INBA/ CENART/CONACULTA/Quinta del Agua Ediciones, 2012.

CORSARO, William A. Sociologia da Infância. Tradução: Lia Gabriele Regius Reis. Porto Alegre: Artmed, 2011. 
DORNELES, Priscila O.; MICELI, Paulinia A. M. A produção cultural elaborada para crianças e sua influência na formação da identidade infantil e o desenvolvimento da curiosidade. Artefactum, ano VIII, n. 01, 2016. Disponível em http://artefactum. rafrom.com.br/index.php/artefactum/article/view/1007. Acesso em: 01 abr. 2019.

ELIA, Ricardo. Aprender experimentando, aprender inventando: A relação entre viagem e educação para Mário de Andrade. Anais IX Congresso Brasileiro de História da Educação, João Pessoa, 2017.

FARIA, Ana L. G. A contribuição dos parques infantis de Mário de Andrade para a construção de uma pedagogia da educação infantil. Educação \& Sociedade, ano XX, n. 69, dez, 1999.

GOIÂNIA. Secretaria Municipal de Educação. Infâncias e Crianças em Cena: por uma Política de Educação Infantil para a Rede Municipal de Educação de Goiânia. Goiânia: SME, 2014.

Secretaria Municipal de Educação. Saberes sobre a infância: a construção de uma política de educação infantil. Goiânia: SME, 2004.

LUKESI, Cipriano C. Ludicidade e atividades lúdicas: uma abordagem a partir da experiência interna. 2005. Disponível em: http://portal.unemat.br/media/ files/ludicidade_e_atividades_ludicas.pdf. Acesso em: 02 out. 2018.

MENGA, Ludke; ANDRÉ, Marli E. D. A. Pesquisa em educação: abordagens qualitativas. São Paulo: EPU, 1986.

PAULA, Roberta C. As danças populares na obra de Mário de Andrade. Resgate, vol. XX, n. 24, jul./dez, p. 36-47, 2012.

OLIVEIRA, Joana A.P. Arte e cultura popular. Brasília, 2011.
OSTETTO, Luciana E. Educação infantil e arte: sentidos e práticas possíveis. Cadernos de Formação da UNIVESP. São Paulo: Cultura Acadêmica. 2011. Disponível em: https://acervodigital.unesp.br/bitstream/123456789/320/1/01d14t01. Acesso em: 03 de ago. 2020.

PIZANI, Rafael S.; JÚNIOR, Edivaldo G.; AMARAL, Silvia C. F. A educação do corpo nos parques e recantos infantis de Campinas. Movimento, Porto Alegre, v. 22, n. 3, p. 707-722, jul./set., 2016.

ROSSETO, Robson. Jogos e improvisação teatral. Guarapuava: Unicentro, 2012.

SÁ, Andreza Lucena Minervino. Pequenos brincantes da Educação Infantil: uma proposta em dança e culturas populares brasileiras. Monografia (Licenciatura em Dança), Universidade Federal de Goiás, 2018.

THIOLENT, Michel. Metodologia da pesquisa-ação. São Paulo: Cortez, 1986.

Recebido: $26 / 12 / 2020$

Aceito: $11 / 05 / 2021$

Aprovado para publicação: 28/05/2021

Este é um artigo de acesso aberto distribuído sob os termos de uma Licença Creative Commons Atribuição 4.0 Internacional. Disponível em: http://creativecommons.org/licenses/by/4.0.

This is an open-access article distributed under the terms of the Creative Commons Attribution License 4.0 International. Available at: http://creativecommons.org/licenses/by/4.0.

Ce texte en libre accès est placé sous licence Creative Commons Attribution 4.0 International. Disponible sur: http://creativecommons.org/licenses/by/4.0. 